\title{
STUDIES ON HYDRALAZINE; EVIDENCE FOR A PERIPHERAL SITE OF ACTION ${ }^{1}$
}

\author{
BY ALBERT STUNKARD,2 LOTHAR WERTHEIMER, AND WALTER REDISCH \\ WITH THE TECHNICAL ASSISTANCE OF LOUISA MULCARE
(From the Research Services, First (Columbia University) and Third (New York University) Medical Divisions, Goldwater Memorial Hospital, and the Departments of Medicine, College of Physicians and Surgeons, Columbia University, and New York
University College of Medicine, New York, N. Y.)

(Submitted for publication December 11, 1953; accepted March 23, 1954)

Since its introduction in 1951, hydralazine (1-hydrazinophthalazine, Apresoline ${ }^{\circledR}$ ) has become a widely used agent for the treatment of hypertensive disease. The mechanism by which it exerts its hypotensive action has not, however, been clearly defined. This is particularly true for the dosage range which is clinically the most relevant, namely, the smallest amount of the drug which will produce a definite hypotensive effect in patients.

According to the most widely accepted theory, the influence of hydralazine is exerted centrally, perhaps in the mid-brain, where it acts to suppress the outflow of sympathetic vasopressor impulses (1-5). It has also been suggested that the drug functions as a ganglionic blocking agent $(2,6)$ and that it acts to produce adrenergic blockade $(3,7$, 8). One investigator (9) has reported the inhibition of a cerebral vasopressor substance by hydralazine. Except for the implication of this latter report, little consideration has been given to the possibility that the drug may act directly upon the blood vessel wall. The following limited series of observations suggest that hydralazine can act directly in this manner to decrease peripheral resistance.

\section{METHODS AND MATERIALS}

Subjects for the blood flow studies consisted of three groups: 1) three patients with uncomplicated hypertensive disease and one hypertensive patient who had largely recovered from a right hemiplegia of two years' duration; 2) four patients with transection of the spinal cord. Complete denervation of the legs was demonstrated by motor and sensory loss below the transection together

1 Supported in part by grants from the Albert and Mary Lasker Foundation, the National Institutes of Health, U. S. Public Health Service and the Public Health Research Institute of the City of New York.

2 Present address: Department of Medicine, Cornell University Medical College, New York, N. Y. with an absence of skin temperature response to the $20.5^{\circ} \mathrm{C}$. of the constant temperature room; 3 ) one hypertensive patient who had undergone unilateral lumbodorsal sympathectomy four years before. Completeness of autonomic denervation was again demonstrated by absence of skin temperature response to a cold stimulus. Studies were performed with subjects in the fasting state and, except for one patient who required $50 \mathrm{mg}$. of Demerol for the relief of pain, none had received any medication the day of the experiment or had smoked for 30 minutes before tests were begun.

Skin temperature and blood flow measurements were carried out in a constant temperature room maintained at $20.5( \pm 1)$ degrees Centigrade with relative humidity between 51 per cent and 57 per cent and wind velocity less than 1 meter per second. The experimental period was of at least three hours' duration, allowing a minimum of two hours' adaptation to the room temperature. Skin temperatures were recorded automatically from the plantar surface of each great toe, the outer surface of each calf and the palmar surface of each middle finger by means of a six point Leeds and Northrup Speedomax which registered the temperature of each point once every 22.5 seconds. Blood flow to forearms and legs was measured by venous occlusion plethysmography using apparatus previously described (10).

Infusion of norepinephrine (Levophedie) before and after administration of hydralazine ${ }^{3}$ was performed in two normotensive patients without evidence of significant organic disease. A $Y$ tube was connected to the infusion needle to allow rapid and easy change from and to the control infusion of isotonic saline. Blood pressure was measured every one to five minutes on the opposite arm by the auscultatory method and mercury sphygmomanometer, and pulse rate was determined at the same time.

Cold pressor tests were performed 23 times on 13 hypertensive subjects before and after intravenous injection of hydralazine. Throughout the test the patients lay quietly on their own beds in a relaxed state, often falling asleep. The hand was immersed in ice water for a period of one minute as described by Hines (11), except for one patient who could not tolerate more than 30 seconds' immersion;

s Hydralazine (1-hydrazinophthalazine, Apresoline(8) was generously supplied by Dr. E. A. Reilly of Ciba Pharmaceutical Products, Inc., Summit, New Jersey. 
TABLE I

Effect of hydralasine on skin temperature and blood flow of the extremities

\begin{tabular}{|c|c|c|c|c|c|c|}
\hline \multirow[b]{2}{*}{ Name } & \multirow{2}{*}{$\begin{array}{c}\text { Dose of } \\
\text { hydralazine } \\
\text { me. }\end{array}$} & \multirow[b]{2}{*}{$\begin{array}{l}\text { Blood pressure } \\
\text { mm. } \mathrm{Hg}_{\mathrm{g}}\end{array}$} & \multicolumn{2}{|c|}{ Skin temperature $\left({ }^{\circ} \mathrm{C}\right)$} & \multicolumn{2}{|c|}{$\begin{array}{l}\text { Blood flow } \\
\text { (cc./min./100 cc. tissue) }\end{array}$} \\
\hline & & & $\begin{array}{l}\text { Left middle } \\
\text { finger }\end{array}$ & $\begin{array}{l}\text { Left great } \\
\text { toe }\end{array}$ & Arm & Leg \\
\hline \multirow{3}{*}{$\begin{array}{l}\text { Control } \\
\text { J. B. } \\
\text { S. S. } \\
\text { J. M. } \\
\text { J. R. } \\
\text { Paraplegics } \\
\text { D. J. } \\
\text { H. R. } \\
\text { C. B. } \\
\text { A. R. } \\
\text { Sympathectomy }\end{array}$} & $\begin{array}{l}15 \\
15 \\
15 \\
15\end{array}$ & $\begin{array}{l}210 / 130-195 / 115 \\
210 / 110-175 / 90 \\
220 / 130-200 / 110 \\
180 / 110-155 / 90\end{array}$ & $\begin{array}{l}22.5-21.5 \\
20.5-19.5 \\
24.0-21.0 \\
24.0-21.0\end{array}$ & $\begin{array}{l}21.5-21.5 \\
22.5-20.5 \\
22.0-21.0 \\
20.0-20.0\end{array}$ & & $\begin{array}{l}2.1-1.1 \\
0.7-0.7 \\
0.9-0.5\end{array}$ \\
\hline & $\begin{array}{l}15 \\
15 \\
15 \\
18\end{array}$ & $\begin{array}{l}120 / 82-120 / 72 \\
154 / 90-152 / 78 \\
140 / 95-115 / 70 \\
115 / 90-115 / 80\end{array}$ & $\begin{array}{l}19.0-19.0 \\
22.5-23.0 \\
23.0-22.5 \\
23.5-23.5\end{array}$ & $\begin{array}{l}33.5-35.5 \\
32.5-34.5 \\
31.5-35.0 \\
32.0-35.0\end{array}$ & $\begin{array}{l}1.0-0.8 \\
1.0-0.8\end{array}$ & $\begin{array}{l}1.8-2.8 \\
3.3-7.3 \\
1.1-1.9 \\
1.0-2.5\end{array}$ \\
\hline & & & $\underset{\text { toe }}{\text { Intact }}$ & $\begin{array}{l}\text { Denervated } \\
\text { toe }\end{array}$ & $\underset{\text { leg }}{\text { Intact }}$ & $\begin{array}{l}\text { Dener- } \\
\text { vated } \\
\text { leg }\end{array}$ \\
\hline \multirow[t]{3}{*}{ A. $\mathbf{M}$. } & 10 & $225 / 114-200 / 106$ & $22.0-22.0$ & $34.0-36.0$ & $0.4-0.3$ & $0.6-2.8$ \\
\hline & & & & & $\begin{array}{c}\text { Intact } \\
\text { foot }\end{array}$ & $\begin{array}{l}\text { Dener- } \\
\text { vated } \\
\text { foot }\end{array}$ \\
\hline & 10 & $210 / 110-195 / 95$ & $23.0-22.5$ & $34.0-36.5$ & $0.8-0.5$ & $2.5-8.4$ \\
\hline
\end{tabular}

blood pressure readings were made every half minute with a mercury sphygmomanometer on the other arm.

\section{RESULTS}

Effects of hydralasine on blood pressure in patients with spinal cord transection: Intravenous administration of $15 \mathrm{mg}$. of hydralazine resulted in falls in diastolic blood pressure ranging from 10 to $25 \mathrm{~mm}$. $\mathrm{Hg}$ in each of four paraplegic patients (Table I). Such responses are comparable to those of subjects with intact nervous systems, and similar initial blood pressure levels. Furthermore, the greatest fall, from $140 / 95$ to $115 / 70$, was noted in the patient (C. B.) with the highest spinal cord transection ( $T$ 1-5). It is worthy of note that the decreases in blood pressure following a constant dose of hydralazine were similar in both the constant temperature room and in the warmer temperature of the ward.

Control measurements of blood flow: Following the intravenous administration of hydralazine in single doses, measurements in four patients with normal innervation of all extremities revealed falls in skin temperature of as much as $3^{\circ} \mathrm{C}$. in the fingers and $2^{\circ} \mathrm{C}$. in the toes with significant reduction in blood flow to the legs in two of three patients (Table I).

Measurements of blood flow in patients with spinal cord transection: Measurements of skin temperature and blood flow were performed in four patients with spinal cord transections to compare the response to hydralazine in the denervated lower extremity with the innervated upper extremity. Intravenous administration of $15 \mathrm{mg}$. of hydralazine (about $0.3 \mathrm{mg}$. per $\mathrm{Kg}$.) was followed by an increase in skin temperature of at least $2^{\circ} \mathrm{C}$. in the toes of each patient, with no significant change

EFFECT OF HYDRALAZINE ON. SKIN TEMPERATURE AND BLOOO FLOW ABOVE AND BELOW SPINAL CORD TRANSECTION

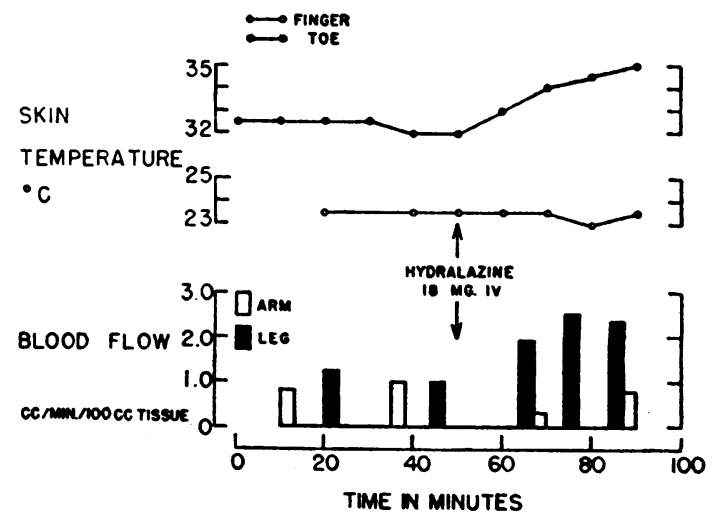

Figure 1

Patient A. R.: Two hours in the constant temperature room prior to 0 time on the graph has resulted in adaptation of the intact finger whose temperature is $23.5^{\circ} \mathrm{C}$. while the denervated toe remains at $32.5^{\circ} \mathrm{C}$. Injection of $18 \mathrm{mg}$. of hydralazine results in a further rise of $3^{\circ} \mathrm{C}$. in the toe, with no change in the finger. Parallel changes are noted in blood flow to the leg and arm. 
in the fingers (Table I). Under the conditions of the experiment, changes of $2^{\circ} \mathrm{C}$. are considered significant (12). Plethysmography showed significant increases in blood flow to the leg in each patient with slight decrease in blood flow to the arm in the two patients so tested (Figure 1).

Measurements of blood flow in patient with unilateral sympathectomy: In an effort to localize the vasodilator activity of hydralazine distal to the T 9 segment of the spinal cord, studies similar to the foregoing were performed on one patient who had four years previously undergone unilateral lumbodorsal sympathectomy. Here the response of the lower extremity on the sympathectomized side was compared with that of its fellow on the intact side in two experiments, measuring blood flow once through the legs and once through the feet. In the first of these experiments (Figure 2) the toe on the sympathectomized side did not adapt to the $21^{\circ} \mathrm{C}$. temperature of the room, but remained at $34^{\circ} \mathrm{C}$. Following injection of $10 \mathrm{mg}$. of hydralazine there was a further rise of $2^{\circ} \mathrm{C}$. in the denervated toe, but none in the intact one, with corresponding findings in blood flow to the legs. A fall in blood pressure from $225 / 114$ to $200 / 106$ was recorded in this experiment.

Norepinephrine infusion: Infusion of 2.4 micrograms per minute of norepinephrine in a normotensive patient resulted in a blood pressure rise of $26 / 18 \mathrm{~mm}$. $\mathrm{Hg}$ and a fall in pulse rate of 5 per minute within 10 minutes (Figure 3). After the infusion was discontinued, and the blood pressure and pulse had returned to pre-infusion levels, intravenous administration of hydralazine resulted in a fall in blood pressure of $0 / 16 \mathrm{~mm}$. $\mathrm{Hg}$ with a rise in pulse rate of 20 per min. At this point infusion of norepinephrine at the same rate as before resulted in a rise in blood pressure of 16/22 with a fall in pulse rate of 16 per min. This response occurred from 30 to 50 minutes following injection of hydralazine, at a time when the effect of the drug is maximal. A second normotensive patient responded in the same way.

Cold pressor studies: Cold pressor tests were performed 23 times in 13 hypertensive patients before and after intravenous doses of hydralazine

\section{EFFECT OF HYDRALAZINE ON SKIN TEMPERATURE AND BLOOD FLOW \\ IN INTACT AND SYMPATHECTOMIZED EXTREMITIES}

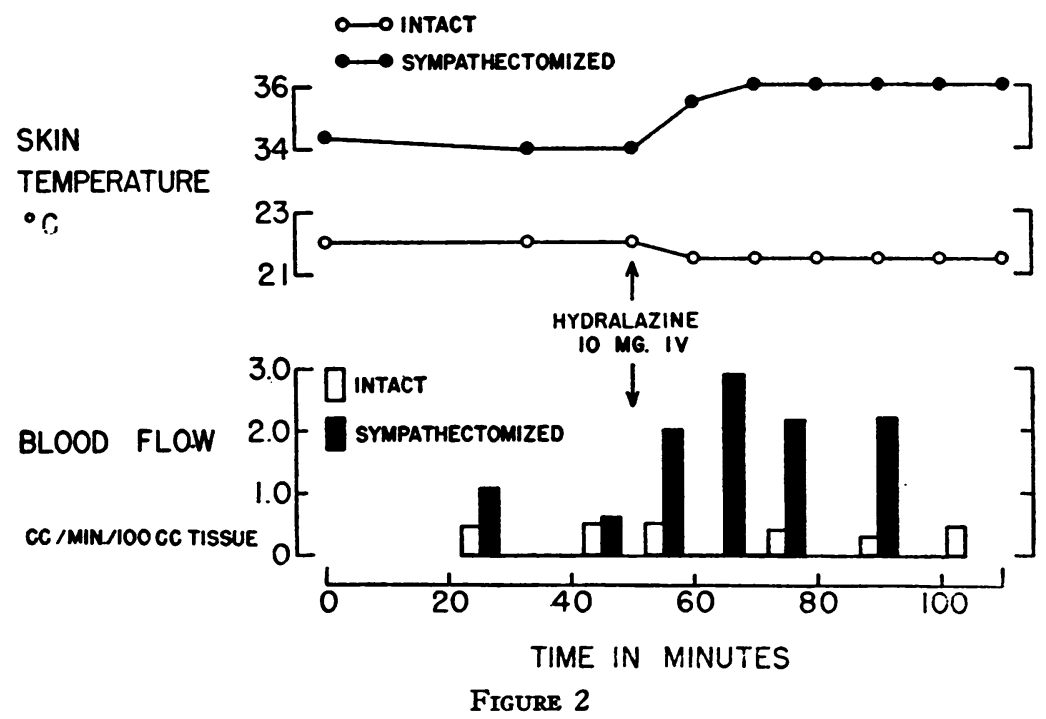

Patient A. M.: Adaptation to the constant temperature room has occurred in the intact toe which is $22^{\circ} \mathrm{C}$. while the sympathectomized one remains at $34^{\circ} \mathrm{C}$. Injection of hydralazine results in a $2^{\circ} \mathrm{C}$. rise in the already warmer extremity, with a $0.5^{\circ} \mathrm{C}$. fall in the intact one. Parallel changes are noted in blood flow to the two legs. 

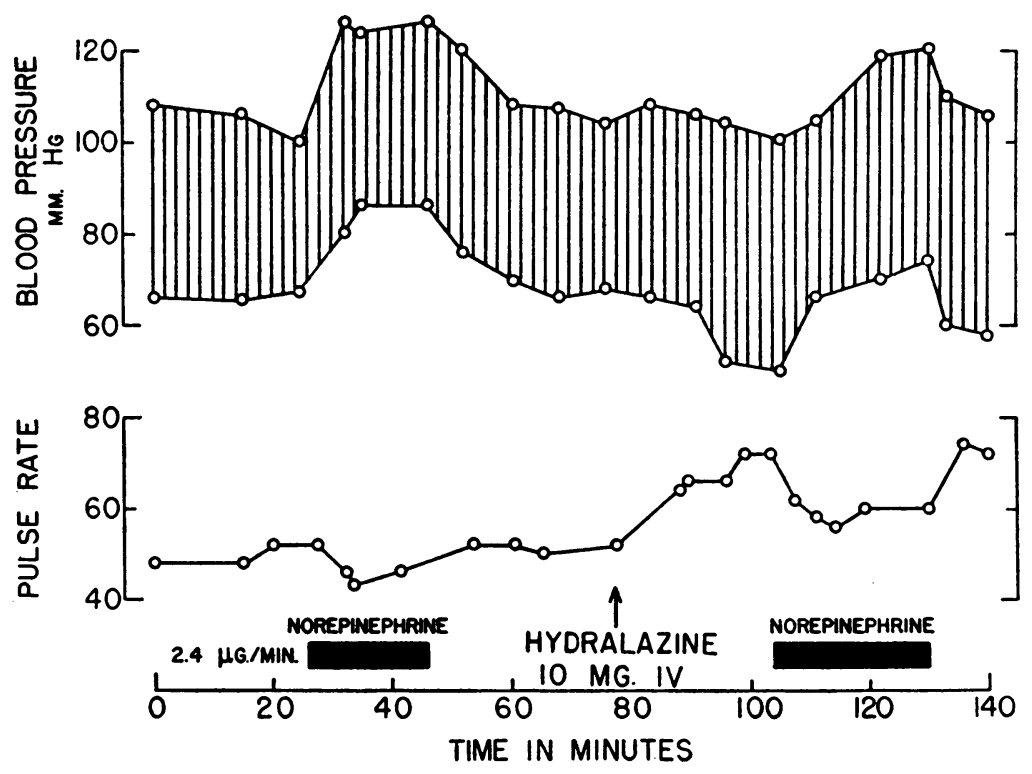

FIGURE 3

Similar rises in blood pressure in response to norepinephrine infusion are found before and after a hypotensive dose of hydralazine. Pulse slowing effect of norepinephrine is not blocked by hydralazine.

COLD PRESSOR RESPONSE BEFORE AND 45 MINUTES AFTER HYDRALAZINE 16 MGMS. IV
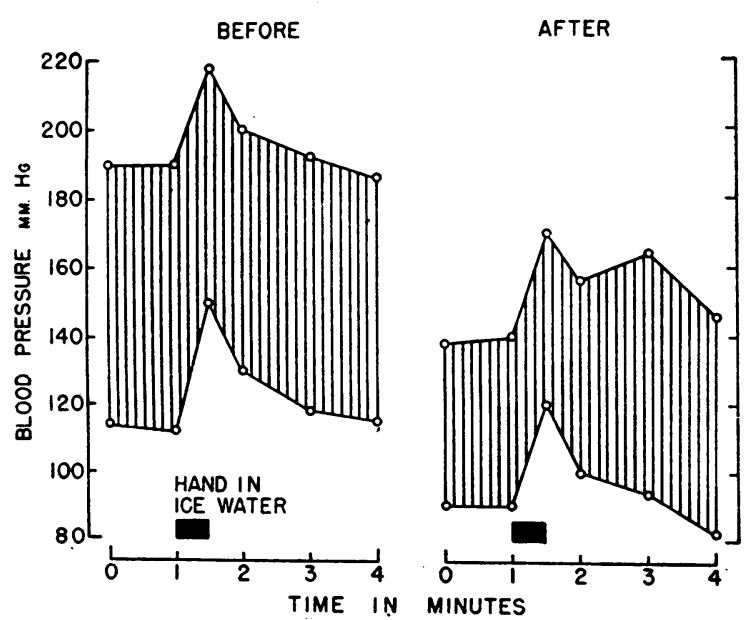

FIGURE 4

A rise in blood pressure of $26 / 38$ is noted in response to immersion of the hand in ice water. Forty-five minutes later, following the administration of $16 \mathrm{mg}$. of hydralazine with a consequent blood pressure fall of $50 / 25$, the cold pressor response is a rise of $30 / 30$. ranging from 8 to $22 \mathrm{mg}$. Of this group 12 tests were performed in eight patients following diastolic blood pressure decreases of at least $10 \mathrm{~mm}$. $\mathrm{Hg}$. During the cold pressor test the average blood pressure rise before hydralazine was $32 / 31$, and after hydralazine $34 / 29$. In no case was there blocking of the response. Eleven tests were performed in eight patients in whom there was no significant fall in diastolic pressure. In this group the average rise during the cold pressor test was $29 / 28$ before the drug and $31 / 17$ afterwards, and the cold pressor test was not blocked in any instance. A typical cold pressor test before and after a hypotensive dose of hydralazine is illustrated in Figure 4. The rise before hydralazine is $26 / 38$, whereas following a fall in diastolic pressure of $25 \mathrm{~mm}$. $\mathrm{Hg}$, the cold pressor rise is $30 / 30$.

\section{DISCUSSION}

The theory of the central action of hydralazine is based on the work of Gross, Druey, and Meier (4), and Craver and Yonkman (13) who showed 
that the drug does not exert a hypotensive effect in the spinal cat. This is supported by reports (2, 14) that hydralazine blocks vasomotor reflexes.

\section{Denervation studies}

Studies comparable to those of Gross, Druey, and Meier, and Craver and Yonkman have not heretofore been performed in man. The results presented here indicate that hydralazine can decrease blood pressure in human subjects with high thoracic spinal cord transections. Furthermore, the drug increases blood flow in extremities denervated either by such transection of the spinal cord or by sympathectomy.

Three explanations of these findings seem possible. First, the increased blood flow may be a result of altered circulatory dynamics, specifically of an increased cardiac output, and thus represent no more than passive adjustment to a greater volume of flow. While hydralazine does increase cardiac output, the increase would appear inadequate to increase blood flow in the denervated extremity in the presence of the decreased blood pressure noted in the present studies.

The second possibility, that these findings result from inhibition of a circulating humoral agent, seems remote in the absence of evidence for such an agent in normotensive subjects.

The third explanation is that hydralazine acts directly upon the blood vessel wall.

The latter hypothesis would account for the otherwise inexplicable finding of Wilkinson, Backman, and Hecht (5) that intra-arterial injection of hydralazine results in a marked increase in skin temperature in the injected extremity, and not in the others, a phenomenon hard to reconcile with a central action of the drug. It does not, however, explain why the vasodilator action is apparent only in denervated limbs, or following intra-arterial injection. There is, of course, the possibility that the action of the drug is a general one on all the blood vessels of the body, but that the greater sympathetic tone under conditions of cold prevents vasodilation from becoming manifest in the normally innervated extremity. This inference may be drawn from the work of Wilkinson, Backman, and Hecht (5) and Grimson, Chittum, and Metcalf (14) who showed an increase in skin temperature following intravenous adminis- tration of hydralazine in a warm room. However, the fact that blood pressure response to a constant dose of the drug is similar in warm and cold environments indicates that vasodilatation of skin vessels is a minor effect of hydralazine.

It is unlikely that action on the blood vessel wall in itself is sufficient explanation for the particular pattern of vasodilatation produced by hydralazine. For, if it were true, drugs with a similar site of action might be expected to effect a similar pattern. And nitrites, which are generally believed to act on the arteriolar wall, are reported to produce peripheral vasodilatation and renal vasoconstriction (15), effects opposite to those of hydralazine.

It would appear necessary to postulate a more potent effect of hydralazine on the visceral than on the cutaneous vascular beds. The widely differing effects of the drug on blood flow in the skin and kidney make this a reasonable hypothesis. Furthermore, it focuses attention on the importance of the visceral vasodilator action of hydralazine and the need for study of its mechanism.

\section{Norepinephrine infusion studies}

Reports of adrenergic blockade by hydralazine $(2,7,8,13,16)$ assume a greater significance with the demonstration of its increased vasodilator activity in denervated extremities, for it raises implications of the heightened adrenergic sensitivity of such structures $(17,18)$. It is, therefore, noteworthy that the doses of hydralazine mentioned in these reports were larger than those found adequate in this study to produce a hypotensive effect. Gross, Druey, and Meier (4), working with cats, has reported that whereas hydralazine in doses of $0.5 \mathrm{mg}$. per $\mathrm{Kg}$. may decrease the rise in blood pressure following epinephrine (but not norepinephrine), $0.1 \mathrm{mg}$. per $\mathrm{Kg}$. has no such effect.

Conflicting reports complicate understanding of this problem. Later, more detailed studies (19) in animals have shown that even very large doses of hydralazine ( 1 to $5 \mathrm{mg}$. per $\mathrm{Kg}$.) affected pressor responses to epinephrine and norepinephrine "minimally, if at all", "left uninfluenced the response of salivation and the nictitating membrane to epinephrine and norepinephrine" and failed to block their action on the seminal vesicle of the guinea pig. It was concluded that hydralazine's "adreno- 
lytic activity would appear to be a secondary characteristic."

The evidence presented above would indicate that doses of hydralazine sufficient to produce a hypotensive effect will not block the hypertensive or pulse-slowing actions of norepinephrine. Such hypotensive activity must, therefore, depend upon a mechanism other than adrenergic blockade.

\section{Cold pressor studies}

Demonstration that a drug can produce vasodilatation by peripheral action does not preclude the possibility that it may act also, and even more significantly, through a central neurogenic mechanism. If such were the case, however, hypotensive doses might be expected to inhibit at least the more prominent sympathetic responses such as the vasopressor reflexes. That hydralazine has such an action is frequently cited on the authority of Freis and Finnerty (2) and Grimson, Chittum, and Metcalf (14) who reported suppression of vasomotor reflexes following its administration. It should be noted, however, that the latter authors, using intravenous doses of as much as 20 to 125 mg., observed blocking of the cold pressor test in only one of five patients and found it unchanged in two.

It is clear that large enough doses of any hypotensive agent will ultimately interfere with responsivity to vasopressor stimuli. The demonstration of such effects following very large doses is, therefore, largely irrelevant to the mode of action of a drug in its therapeutic range.

In the present study, hypotensive effects were achieved 13 times with little if any suppression of the cold pressor test. Accordingly, it was concluded that the hypotensive activity of hydralazine in these instances did not depend upon its suppression of those vasopressor stimuli which determine the cold pressor reflex. This observation would also appear to cast doubt upon the theory of central action of hydralazine, and suggests that its major site of action may be the peripheral one previously demonstrated.

\section{SUM MARY}

1. Hydralazine in doses of $0.3 \mathrm{mg}$. per $\mathrm{Kg}$. lowered the blood pressure of four subjects with spinal cord transection as high at $\mathrm{T}$ 1-5.
2. Hydralazine increased blood flow in extremities denervated by spinal cord transection and sympathectomy. Such increases were not found in normally innervated extremities.

3. Doses of hydralazine sufficient to lower blood pressure did not interfere with the subsequent hypertension and bradycardia produced by norepinephrine infusion.

4. Hypotensive doses of hydralazine did not interfere with the rise in blood pressure produced by the cold pressor test.

5. It is concluded that hydralazine can act directly upon the blood vessel wall to produce vasodilatation, and that this may be its major site of action.

\section{REFERENCES}

1. Yonkman, F. F., Neurogenic hypertension; chemical approaches to its amelioration. J. Mich. State Med. Soc., 1951, 50, 160.

2. Freis, E. D., and Finnerty, F. A., Jr., Suppression of vasomotor reflexes in man following L-hydrazinophthalazine (C-5968). Proc. Soc. Exper. Biol. \& Med., 1950, 75, 23.

3. Moyer, J. H., Handley, C. A., and Huggins, R. A., Some pharmacodynamic effects of 1-hydrazinophthalazine (C-5968) with particular reference to renal function and cardiovascular response. $\mathrm{J}$. Pharmacol. \& Exper. Therap., 1951, 103, 368.

4. Gross, F., Druey, J., and Meier, R., Eine neue Gruppe blutdrucksenkender Substanzen von besonderem Wirkungscharakter. Experientia, 1950, 6, 19.

5. Wilkinson, E. L., Backman, H., and Hecht, H. H., Cardiovascular and renal adjustments to a hypotensive agent (1-hydrazinophthalazine: Ciba BA5968: Apresoline). J. Clin. Invest., 1952, 31, 872.

6. Schroeder, H. A., The effect of 1-hydrazinophthalazine in hypertension. Circulation, 1952, 5, 28.

7. Freis, E. D., MacKay, J. C., and Oliver, W. F., The effects of "Sympatholytic" drugs on the cardiovascular responses to epinephrine and norepinephrine in man. Circulation, 1951, 3, 254.

8. Grimson, K. S., Orgain, E. S., Rowe, C. R., Jr., and Sieber, $H$. A., Caution with regard to use of hexamethonium and "apresoline." J. A. M. A., 1952, 149, 215.

9. Taylor, R. D., Page, I. H., and Corcoran, A. C., A hormonal neurogenic vasopressor mechanism. A. M. A. Arch. Int. Med., 1951, 88, 1.

10. Redisch, W., Wertheimer, L., Delisle, C., and Steele, J. M., Comparison of various vascular beds in man; their responses to a simple vasodilator stimulus. Circulation, 1954, 9, 63.

11. Hines, E. A., Jr., Technic of the cold pressor test. Proc. Staff Meeting, Mayo Clinic, 1939, 14, 185. 
12. Redisch, W., Sheckman, E., and Steele, J. M., Skin temperature response of normal human subjects to various conditions. Circulation, 1952, 6, 862.

13. Craver, B. N., and Yonkman, F. F., Some pharmacological properties of L-hydrazinophthalazine, a hypotensive agent. Federation Proc., 1950, 9, 265.

14. Grimson, K. S., Chittum, J. R., and Metcalf, B. H., Actions of L-hydrazinophthalazine (C-5968) on vasomotor reflexes and hypertension in dogs and man. Federation Proc., 1950, 9, 279.

15. Chasis, H., Ranges, H. A., Goldring, W., and Smith, $H$. W., The control of renal blood flow and glomerular filtration in normal man. J. Clin. Invest., 1938, 17, 683.
16. Britton, J. B., Taylor, J. P., and Ahlquist, R. P., Cardiovascular actions of 2, 3,-benzodiazine-4hydrazine. Federation Proc., 1951, 10, 282.

17. Meltzer, S. J., and Meltzer, C., The share of the central vasomotor innervation in the vasoconstricttion caused by intravenous injection of suprarenal extract. Am. J. Physiol., 1903, 9, 147.

18. Cannon, W. B., and Rosenblueth, A., The sensitization of a sympathetic ganglion by preganglionic denervation. Am. J. Physiol., 1936, 116, 408.

19. Craver, B. N., Barrett, W., Cameron, A., and Yonkman, F. F., The activities of 1-Hydrazinophthalazine (Ba-5968), a hypotensive agent. J. Am. Pharm. A., 1951, 40, 559. 